\title{
Biological notes on some egg parasitoids of Phaneroptera nana Fieber, 1853 (Orthoptera Tettigoniidae) with description of a new species of Aprostocetus Westwood, 1833 (Hymenoptera Eulophidae) from Italy
}

\author{
Gennaro Viggiani \\ Via Madonna della Salute 4, 80055 Portici, Napoli; email: viggenriv@gmail.com
}

\begin{abstract}
The author provides an account on the known egg parasitoids of Phaneroptera Serville, 1831 (Orthoptera Tettigoniidae). New records and biological notes on Anastatus bifasciatus (Geoffroy, 1785), Pseudoligosita phaneropterae (Viggiani, 1981) and Aprostocetus brevifrangiatus n. sp. (Hymenoptera Eulophidae), egg parasitoids of Phaneroptera nana Fieber, 1853 in Italy, are given.
\end{abstract}

KEY WORDS Egg parasitoids; Anastatus; Aprostocetus; Baryconus; Pseudoligosita.

Received 28. 01.2021; accepted 19.03.2021; published online 23.04.2021

\section{INTRODUCTION}

An account on the biology, host plants, feeding and oviposition behavior of Phaneroptera nana Fieber, 1853 (Orthoptera Tettigoniidae) has been given by Massa \& Rizzo (1998). The species is widely distributed in southern Europe and north Africa, and develops one generation a year. Egg laying takes place in the leaf lamina of several plants during autumn. The records of the egg parasitoids of Phaneroptera spp. are scanty. Silvestri (1934) refers that the eggs are parasitized by several Chalcidoidea, mostly Trichogrammatidae. Grandi (1951) reports Trichogramma evanescens Westwood, 1833 (Hymenoptera Trichogrammatidae) among the egg parasitoids of Phaneroptera Serville, 1831, but the record is uncertain and need to be confirmed. Bin (1976) recorded some species of Baryconus Förster, 1856 (Hymenoptera Scelionidae), Viggiani \& Tremblay (1978) reported on the emergence of Anastatus bifasciatus (Geoffroy, 1785) (Hymenoptera Eupelmidae) from eggs of Phaneroptera sp. and Vig- giani (1981) described the species Pseudoligosita phaneropterae (Viggiani, 1981) (Hymenoptera Trichogrammatidae). Torreno \& Raguian (1987) reports a Scelio sp. (Hymenoptera Scelionidae) as egg parasitoid of Phaneroptera furcata Stål, 1861.

In the past decades, since 1969, I have collected several eggs of Phaneroptera, mostly of P. nana, in several locations of southern Italy, from which parasitoids emerged. Some eggs, inserted in the leaf lamina of several plants, mostly of olive tree, were dissected in different period of the year to follow the biology of the parasitoids. Among the parasitoids a new species of Aprostocetus Westwood, 1833 (Hymenoptera Eulophidae) has been identified and here described.

\section{MATERIAL AND METHODS}

Eggs of Phaneroptera nana (Figs. 1-3) were collected on several plants and periods of the year. They were singly isolated in vials and maintained at room 
temperatures. Some eggs were dissected to collect data on the biology of the parasitoids. The specimens emerged were slide-mounted in Canada balsam phenol, but some of them were mounted on pin cards. All the material was examined under a Leica stereoscope and a Zeiss Axiophot with mounted phase contrast. Both instruments were used also to take pictures by using a Canon Powershot S45 camera. The drawings were taken by a camera lucida.

The nomenclature follows Graham (1987). The material recorded in this paper will be deposited in the entomological collection of the "Dipartimento di Agraria dell'Università degli Studi - Federico II", Portici, Napoli, Italy.

\section{RESULTS}

The emerged parasitoids from the eggs of $P$. nana were identified as reported below.

\section{Anastatus bifasciatus (Geoffroy, 1785)}

Material eXaminated. 4 females and 1 male, Castelvenere (Benevento, Italy), 28.I.1971, ex eggs of Phaneroptera nana in olive leaves, coll. G. Viggiani, laboratory emergence IV-V.1971; 1 female, Rivello (Potenza, Italy), IX-X.2010, ex egg of $P$. nana in grapevine leaf, coll. G. Viggiani, laboratory emergence 3.VI.2011; 1 female, Calvi Risorta (Caserta, Italy), 23.VIII.1989, ex egg of P. nana in peach leaf, coll. G. Viggiani.

REMARKS. The species is a primary parasitoid or hyperparasitoid of a wide range of hosts, normally at egg stage, but some adaptations to analogous hosts are recorded (Viggiani \& Tremblay, 1978; Noyes, 2021). Several specimens have been reared from eggs of $P$. nana, as solitary parasitoids. The exit hole of the parasitoid from the host egg has a diameter of $0.4 \mathrm{~mm}$. The life cycle of A. bifasciatus is not synchronized with that of its host. From eggs of P. nana collected in winter 1971, adults of $A$. bifasciatus emerged in spring of the same year. Specimens emerged also in autumn.

Pseudoligosita phaneropterae (Viggiani, 1981) (Fig. 4)

Material exAminated. 19 females and 2 males, Portici (Naples, Italy), 21.III.1969, labora- tory emergence, 22.IX.1969, ex egg of P. nana in leaf of Viburnum tinus, coll. G. Viggiani. 3 females, Portici, 17.X.2011, yellow traps, coll. G. Viggiani.

Distribution. Basilicata (Rivello, Potenza, Italy); Campania (Maiori, Portici, Tramonti, Naples, Italy); Calabria (Cassano allo Jonio, Cosenza, Italy).

Biological NOtes. The species resulted an endophagous, gregarious egg parasitoid. From each host egg emerge several specimens, females and males (in one case 19 females and 2 males). The life cycle of the parasitoid is synchronyzed with that of the host, through a long period from autumn to autumn of the next year, mostly under diapausing larvae and pupae. This was proved by dissecting some host eggs and also maintaining some eggs collected during winter and subsequent months at laboratory temperatures; in all cases adults of $P$. phaneropterae emerged in September-October of the same year, from one (round of $0.3 \mathrm{~mm}$ of diameter) or more exit holes opened in each host egg (Fig. 5). This biological traits suggest that the trichogrammatid should be specific or associated with hosts biologically similar to P. nana.

REMARKs. This species was described under the genus Oligosita Walker (Viggiani, 1981) and subsequently never recorded.

Aprostocetus brevifrangiatus n. sp. (Figs. 6-12)

https://zoobank.org:act:9C82ADD4-3277489C-8201-0B5DF42FA0D1

Material EXAmined. Holotype female (on slide), Pignataro maggiore (Caserta, Italy), 13.IX.1989, laboratory emergence, 28.IX.1989, ex egg of Phaneroptera nana in peach leaf, coll. G. Viggiani. Paratypes, 5 females and 6 males, same data of holotype. 1 female, Castelvenere (Benevento, Italy), 28.I.1971, laboratory emergence, IV-V.1971 ex eggs of $P$. nana in olive leaf, coll.G. Viggiani.

Description OF the holotyPe. Female. Body mostly yellow or yellow-ochre. Head yellow, stemmaticum dark, ocelli and eyes dark red. Occipital area, pronotum, base of scapula, axilla, and basal half of mid lobe of mesoscutum, dark or yellowochre, sometimes with green luster, mainly on pronotum; tegula yellow; metanotum and propodeum, ventral side of the thorax, brown (Fig. 


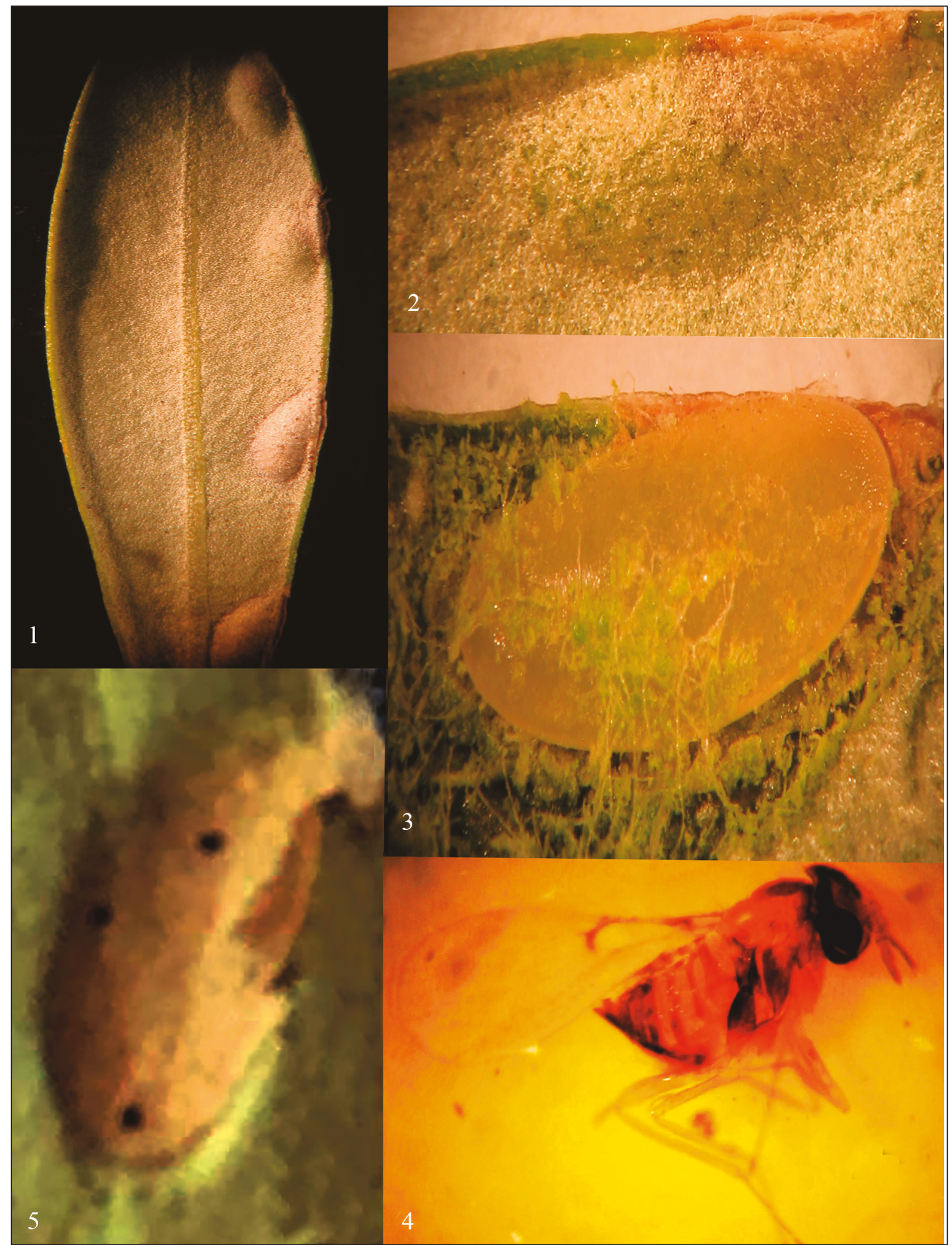

Figures 1-5. Phaneroptera nana. Fig. 1: eggs inserted laterally in the lamina of an olive leaf. Fig. 2: egg deposited, in side view. Fig. 3: egg showed without the covering leaf tissues. Fig. 4: Pseudoligosita phaneropterae, female. Fig. 5: egg of $P$. nana with exit holes of $P$. phaneropterae. 
6). Antenna with yellow scape and pedicel, dorsally brown, and greysh or brown flagellum. Wings hyaline and legs completely yellow. Gaster mostly yellow, with a dark band including the tergites 3-5. Length: $1.0 \mathrm{~mm}$.

Head $3 \times$ as wide a long; POL as wide or slightly wider than OOL; mandible 3-toothed; maxillary and labial palp one-segmented; malar sulcus straight and shallow, without a fovea; gena shorter than eye height (4:7), about as long as eye length. Short and rather dense setae on vertex, between stemmaticum and posterior margin of eye. Antenna (Fig. 7) inserted at or just above the level of the eye ventral margin; scape reaching the vertex level; radicle subquadrate, scape elongate, $3.6 \times$ as long as wide, pedicel twice as long as wide, $0.4 \times$ as long as scapus, 3 anelli, funicle $1.6 \times$ as long as clava, 3-segmented, F1 $1.5 \times$ as long as wide, F2 and F3 subequal to F1, clava not wider than funicle, apparently 2-segmented, with $\mathrm{C} 2+\mathrm{C} 3$ fused, $\mathrm{C} 1$ shorter than $\mathrm{F} 3$ (25:30), $\mathrm{C} 2+\mathrm{C} 3$ as long as F3 with terminal spine rather long, $0.25 \times$ as long as $\mathrm{C} 2+\mathrm{C} 3$; funicle and clava segments each with 3-5 linear sensilla and some setae not longer than the corresponding segment. Mesosoma (Fig. 6) slightly longer than wide (17:15). Pronotum short, about as long as head length, with several setae, longer on the posterior part. Mid lobe of mesoscutum subtrapezoidal, longer than wide (9:6), without median sulcus, with a row of 3 adnotaular setae on each side. Scutellum shorter than mid lobe of mesoscutum (6:9), with 2 pairs of setae inserted very near the submedian lines, distance between the submedian lines about as the distance between sublateral line and submedian line. Fore wing (Fig. 8) $2 \times$ as long as wide; costal cell $2 \times$ as long as stigmal vein; submarginal vein slightly shorter than marginal vein (8:9); premarginal vein shorter than stigmal vein $(15: 18)$, marginal vein $2.75 \times$ as long as stigmal vein; subcubital vein reaching the level of the distal angle of the speculum; discal blade with rather dense ciliation and short fringe, not longer than half stigmal vein. Hind wing (Fig. 9) pointed, with dense ciliation from base of the marginal vein and fringe $0.25 \times$ of the discal width. Dorsellum about as long as half propodeum. Propodeum about $4 \times$ as wide as long, posteriorly rather emarginated, with a rather short median carina; spiracles circular, separated from the hind margin of metanotum by about half of the their diameter, with 2 paraspiracular setae. Legs normal with fore coxa pear-shaped, about twice as long as wide; middle coxa as long as wide; hind coxa pear-shaped at least twice as long as wide; middle spur about as long as corresponding basitarsus; tarsomeres subequal.

Gaster ovate (Fig. 6), 1.5× as long wide, slightly longer than mesosoma (5:4), with short and transverse petiole; rather dense setation on tergites 2-5; cercoid with two subequal long setae; postercale length about as long as the distance between cercoids; postcercale plus ovipositor sheaths only $0.2 \times$ the hind tibia; hypogynium reaching about the middle of gaster; ovipositor not exerted, $1.5 \times$ longer than hind tibia: 3 th valvula $0.28 \times$ as long as the total length of the ovipositor.

VARIABILITY. The other female paratypes do not show substantial morphological differences with the holotype: length: 1.1-1.2 mm, scape 3.7 as long as wide, fore wing $2 \mathrm{x}$ as long as wide, costal cell $2.5 \mathrm{x}$ as long as stigmal vein, marginal vein $2.25 \mathrm{x}$ as long as stigmal vein, gaster $1.7 \mathrm{x}$ as long as wide; some specimens with a baso-lateral narrow brown stripe on each side.

The male paratypes have color and morphological characters mostly as the female. Head with occipital area yellow as the antennae, pronotum with dark color only anteriorly, thorax with or without dark color. Length: 0.9-1.0 mm. Antenna (Fig. 10) with scape $2.3 \times$ as long as wide, ventral sensorial plaque extended from the basal $1 / 5$ of the scape margin to near its distal end, pedicel long as half of scape, as long as F1, 3 very short anelli, funicle 4segmented, with subequal segments, $1.4 \times$ as long as wide, each with 2-3 linear sensilla and some setae not in compact whorl and not longer than the corresponding segment; clava as long as F3 and F4 combined, with $\mathrm{C} 1$ well marked from $\mathrm{C} 2$ and $\mathrm{C} 3$, the latter mostly fused with the preceding segment and with a rather long spine, about half the corresponding segment. Gaster oblong (Fig. 11), 1.7$2.2 \times$ as long as broad. Genitalia (Fig. 12) length $0.15 \mathrm{~mm}$, typical of the genus, with narrow parameres and laminar volsellae with a digital spine.

ETyMology. The name refers to the short fringe of the fore wing.

BiologicAl nOtes. The species is gregarious. Probably the eggs of $P$. nana on peach leaves, a deciduous host plant, are deposited in summer, at beginning of the period of the host oviposition, when 

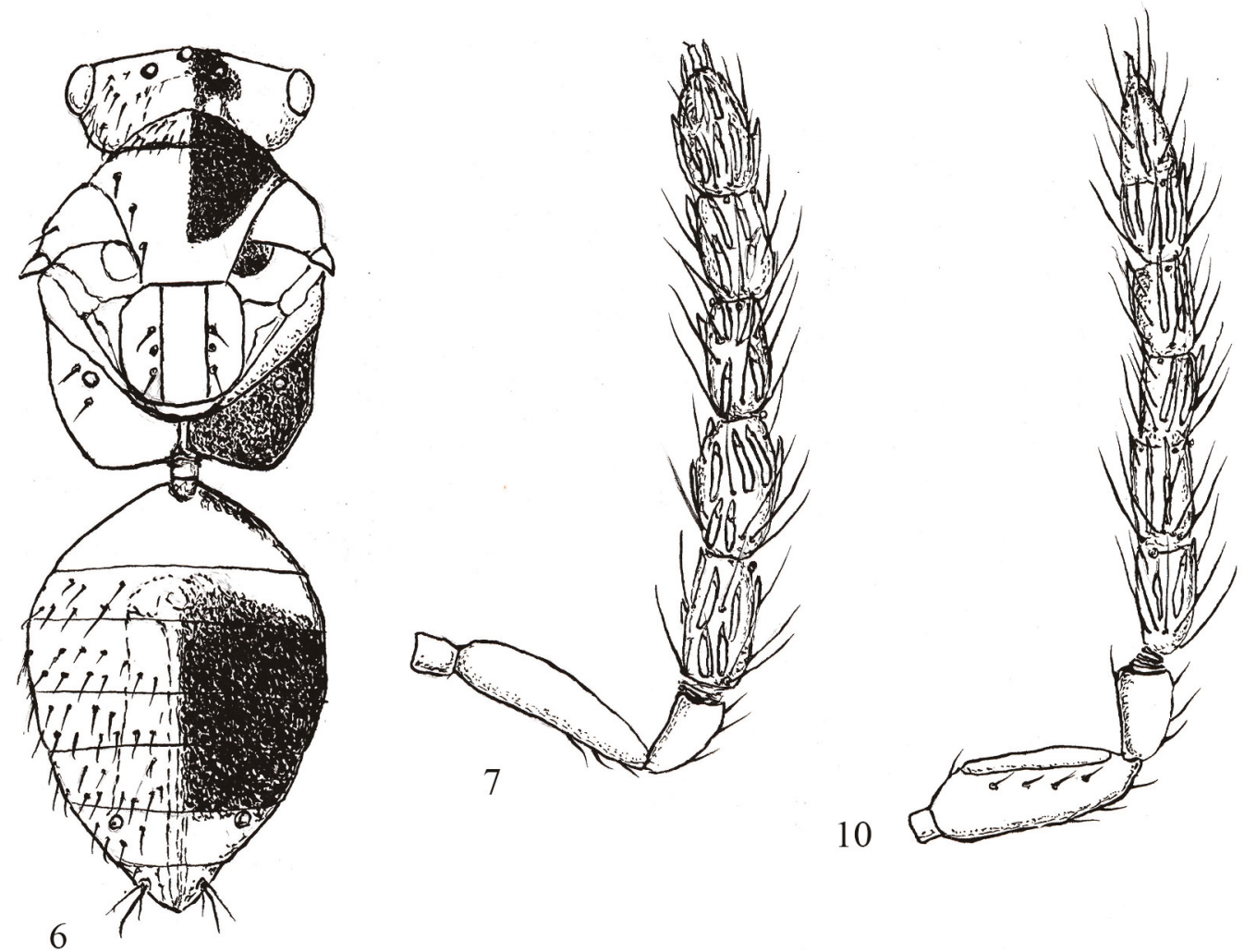

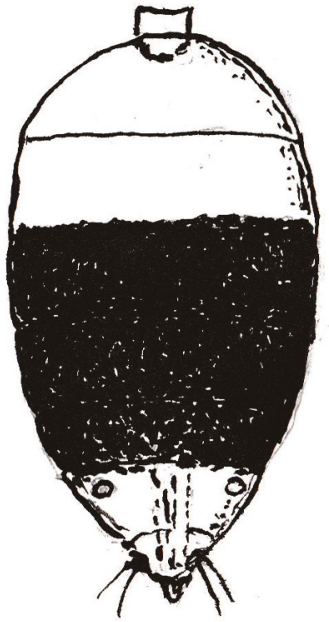

11

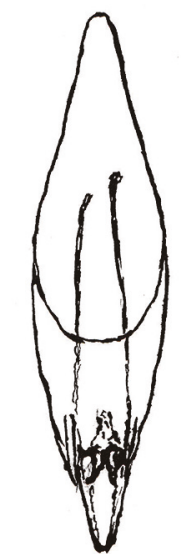

10
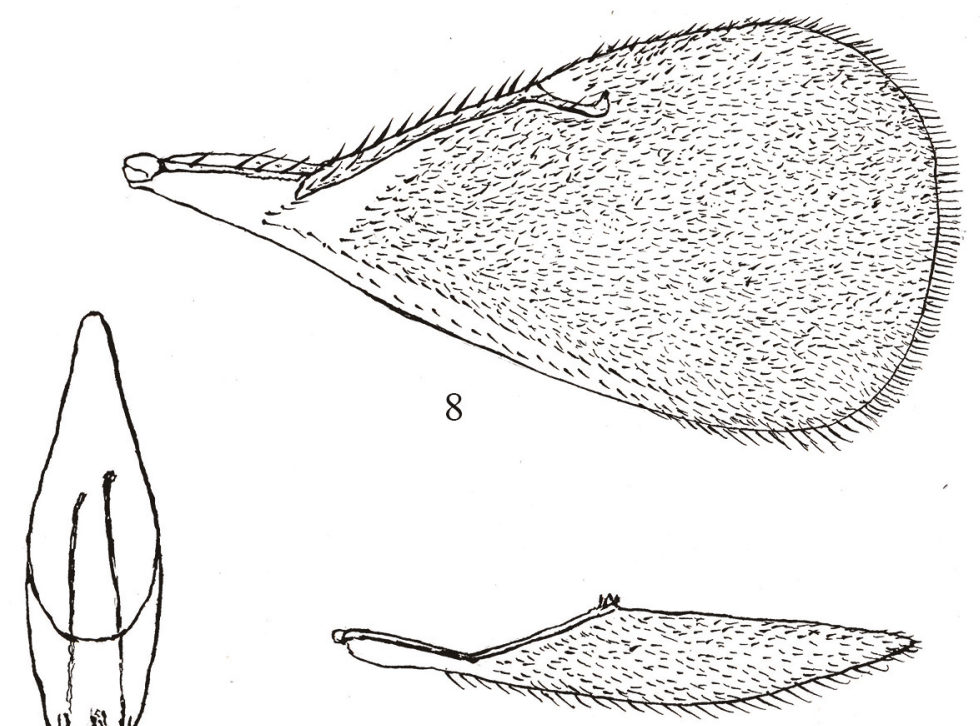

9

Figures 6-9. Aprostocetus brevifrangiatus n. sp. holotype female. Fig. 6: sketch of the body (left half with setation, right half with dark patches). Fig. 7: antenna. Fig. 8: fore wing. Fig. 9: hind wing. Figures 10-12. Aprostocetus brevifrangiatus n. sp. paratype male. Fig. 10: antenna. Fig. 11: gaster. Fig. 12: genitalia. 
they are parasitized by $A$. brevifrangiatus. The adults of the parasitoid emerge in autumn (September-Octber) and can oviposit on fresh host eggs inserted in leaves of evergreen plants. The life cycle of the eulophid, according to the collected data is not synchronized with that of the host.

Distribution. Currently, this new species is known only for the type localities.

REMARKS. According to the keys to the genus of European Tetrastichinae (Graham, 1987, 1991) the species is included in Aprostocetus, subgenus Aprostocetus. Among the species-group reported by Graham (1987) the new species is provisionally included in the pausiris-group, rather heterogeneous and charaterized in having the long seta of each cercoid equal in length to or a little longer than the next longest seta. Among the at least partially yellow species included in this group, A. bucculentus (Kostjukov), 1978), A. crassiceps Graham, 1987 and $A$. tompanus (Erdös), 1954, the new species is more near $A$. crassiceps, but the latter species shows antenna with longer F2 and F3, uniseriate sensilla, club distinctly broader than F3 and clearly 3 -segmented.

In the key to males of Aprostocetus by Graham (1987) the new species runs near A. flavifrons (Walker, 1849), but the latter species shows ventral plaque fully one-third length of scape, placed on distal half of the ventral margin, and other differences.

The present is the first record of an Aprostocetus egg parasitoid of Orthoptera Tettigoniidae in Europe. Aprostocetus dubius Waterston, 1929, parasitizing eggs of Segestes decoratus Redtenbacher, 1892 , is the only known species associated with tettigoniids in Papua New Guinea, but the mentioned species belongs to Aprostocetus subgenus Ootetrastichus Perkins, 1906.

\section{DISCUSSION AND CONCLUSIONS}

According to the data reported in the present paper, the complex of egg parasitoids associated with $P$. nana varies in time and space. The included species belong to several families (Eulophidae, Eupelmidae, Scelionidae and Trichogrammatidae). The host eggs can bee oviposited in leaves of both evergreen (Olea europaea, Citrus lemon, Viburnum tinus, Hedera helix, ecc.) and deciduous plants (Prunus persica, Vitis vinifera, Castanea sativa, ecc.). In the first case fresh eggs of $P$. nana can be found from June-July, when new adults of the year start to be present, and more frequently to September-November. At present, one parasitoid, namely P. phaneropterae, shows a biology strictly synchronized with the egg deposition of the host. The females of the trichogrammatid oviposit in the host egg in autumn and a long development takes place until the autumn of the next year, when the new adults emerges. The mentioned synchronization is regulated by a process of diapause. In fact the variations of temperatures tested in the laboratory did not remove the mentioned process. No emergence of this parasitoid has been recorded in spring-summer, when the healthy host eggs hatch. $P$. phaneropterae is probably host specific of $P$. nana or oligophagous on biologically allied hosts, but not able to parasitize the eggs of the mentioned hosts oviposited on deciduous plants.

On the contrary, other parasitoids (Aprostocetus, A. bifasciatus, Baryscapus sp.) of P. nana, ovipositing in the host eggs in autumn, complete a generation in the next spring-summer. They can then develop another generation on the same host in summer-autumn.

On deciduous host plants, P. nana can oviposit eggs in developed leaves in summer. These eggs can be parasitized by parasitoids that complete one generation in next autumn. The emergence data concerning $A$. bifasciatus and $A$. brevifrangiatus support the mentioned behavior.

\section{REFERENCES}

Bin F., 1976. New host records in Baryconus Foerster (Hymenoptera, Scelionidae). Entomologica, 12: 6366.

Graham M.W.R. de V., 1987. A reclassification of the European Tetrastichinae (Hymenoptera Eulophidae), with a revision of certain genera. Bulletin of the British Museum (Natural History) (Entomology), 55: 1-392.

Graham M.W.R. DE V., 1991. A reclassification of the European Tetrastichinae (Hymenoptera: Eulophidae): revision of the remaining genera. Memoirs of the American Entomological Institute, 49: 1-322 pp.

Grandi G., 1951. Introduzione allo studio dell'Entomologia, Vol. 1. Edizioni agricole, Bologna, 950 pp. 
Massa B. \& Rizzo M.C., 1998. Osservazioni sull'ovideposizione di Phaneroptera nana Fieber 1853 (Orthoptera: Tettigoniidae). Phytophaga, 8: 49-56.

Noyes J.S., 2021. Universal Chalcidoidea Database. World Wide Web electronic publication: http://www.nhm.ac.uk/chalcidoids

Silvestri F., 1934. Compendio di Entomologia applicata. Tipografia Bellavista, Portici, Vol. 1, part 1, 448 pp.

Torreno H. S. \& Ruguian Z. C., 1987. The biology and behaviour of the katydid Phaneroptera furcifera Stål on tobacco. Philippine Entomologist, 7: 167-176.
Viggiani G., 1981. Note su alcune specie di Oligosita Walker (Hym. Trichogrammatidae) e descrizione di quattro nuove specie. Bollettino del Laboratorio di Entomologia Agraria "Filippo Silvestri", 38: 125132.

Viggiani G. \& Tremblay E., 1978. Nuovi reperti sulla specializzazione morfotipica di Anastatus bifasciatus (Geoffroy) (Eupelmidae) agli ospiti. Ricerche sugli Hymenoptera Chalcidoidea. XLVI. Atti XI Congresso Nazionale Italiano di Entomologia, PorticiSorrento, 10-15 maggio 1976: 321-322. 
